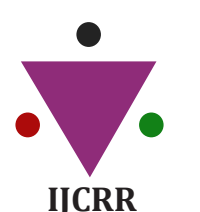

IJCRR

Section: Healthcare

Sci. Journal Impact

Factor: 6.1 (2018)

ICV: 90.90 (2018)

(c) (i) (3)

Copyright@IJCRR

\section{Medical and Organizational Measures to Improve the Provision of Medical Care in the Dermatovenerology Profile}

\author{
Rizaev JA', Ashirov ZF², Toshev SU', Islamov NH3 , Salamova LA', Baratova MR \\ 'Doctor of Medical Sciences, Professor, Rector of the Samarkand State Medical Institute, Uzbekistan; ${ }^{2}$ Head of the Department of Dermatoven-

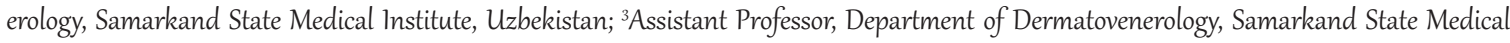 \\ Institute, Uzbekistan.
}

\title{
ABSTRACT
}

Introduction: Most Dermatovenerological diseases belong to the category of socially significant diseases.

Objective: To improve the organization of medical care for Dermatovenerological patients and improving their health.

Methods: The present study was carried out within 2 years from 2018-2019 at the DS of the Samarkand region. Legislative and regulatory acts of the Federal and regional levels, local self-government bodies; literature data on the experience of creating management systems were evaluated.

Results: In this regard, changes in the country's socio-economic development affect the epidemiological situation and the quality of medical care. Historical experience shows that any socio-economic changes in society entail the need to modernize the existing system.

Conclusion: In the third millennium, the state of the epidemiological situation and socio-economic development of society indicates the need to manage the quality of medical care, improve the organizational basis for the prevention of Dermatovenereological care to the population.

Key Words: Dermatovenerological service, Quality medical care, Work motivation of Dermatovenerologists

\section{INTRODUCTION}

The analysis of domestic and foreign experience in organizing the provision of dermatological care to the population allows us to conclude that this topic is only partially covered. Since some problematic issues are not sufficiently covered, they require further development. ${ }^{1,2}$ At the present stage, the problems of improving the quality of medical care and the effectiveness of the Dermatovenerological service (DS), using process-oriented management methods, including the organization of an effective system of intradepartmental interaction, are relevant. ${ }^{3,4}$

The issues related to the study of the interaction between Dermatovenereologists of specialized skin and venereal institutions and doctors of various specialities in dermatological practice are insufficiently studied. We have found only a few works on the interaction of doctors and integration of the DS with obstetric-gynaecological, urological, sanitaryepidemiological, psychiatric, infectious and other services. ${ }^{1,2}$ The above has determined the expediency of this study, indicated its relevance and practical significance in modern conditions.

Based on a comprehensive study of the system of medical care for patients in the "Dermatovenerology" profile to scientifically substantiate, evaluate the effectiveness of the system of medical and organizational measures to improve the interaction of a Dermatovenerologist with doctors of other specialities, aimed at improving the organization of medical care for Dermatovenerological patients and improving their health. The object of study was the structure (classrooms, offices, dispensary), which have a population of dermatological assistance, control system DS and intra-agency interaction of doctors.

\section{Corresponding Author:}

Rizaev JA, Doctor of Medical Sciences, Professor, Rector of the Samarkand State Medical Institute, Uzbekistan.

ISSN: 2231-2196 (Print)

Received: 25.07 .2020
ISSN: 0975-5241 (Online)

Revised: 29.09 .2020
Accepted: 09.11 .2020
Published: 14.12 .2020 


\section{MATERIALS AND METHODS}

The DS of the Samarkand region was chosen as the research base. The present study was carried out within 2 years from 2018-2019. A set of medical and organizational measures that develop in the process of providing Dermatovenerological care to the population, including intradepartmental interaction of Dermatovenerologists and doctors of other specialities.

The materials of the study were legislative and regulatory acts of the Federal and regional levels, local self-government bodies; literature data on the experience of creating management systems, statistical data on the performance of the regional DS, its resource and personnel potential and funding.

To solve the tasks set, the researchers used modern methods: obtaining information from primary medical accounting and reporting documentation and from official sources, statistical, expert assessment, analytical, and organizational modelling.

\section{RESULTS}

The organizational structure of the DS in our region was built on a functional basis and submitted to independent medical institutions (dispensaries) and the structural units (offices, branches), as well as a hierarchical control system DS, headed by the chief expert, chief physician regional Dermatovenerological clinic.

Process models of healthcare management are widely used in modern management practice. ${ }^{2}$ Largely, the conditions formed in the DS of the region corresponded to the method of constructing a process-oriented scheme for the functioning of the service using elements of process management.

To switch to a process-oriented scheme of functioning of the dermato-venereal service, it was necessary to analyze and streamline existing processes (stages of the service, powers and responsibilities, provision of resources). To implement this task, the working group prepared a "monitoring Questionnaire".

Special attention is paid to the organization of interaction between primary medical care and Dermatovenerologists. Therefore, a method was developed for calculating the required number of consultations of narrow primary-level specialists for the next year. Calculations were carried out for each nosological form (ICD code): the predicted number of patients per year was calculated, which consisted of the number of newly detected cases (the average annual number of visits according to statistical forms No. 025a for 2018-2019) and the number of dispensary group of patients; average indicators of the frequency of providing consultations. For example, in 2018, 904 patients (with atopic dermatitis-501, urticaria-350, and Toxicoderma-53) will need to be consulted by an allergist-immunologist. The required number of consultations with a rheumatologist next year will be 179 (78 patients with scleroderma, 78 with lupus erythematosus, 5 with nodular erythema, and 18 with arthropathic psoriasis).

By 2018, the region has developed certain problems of interaction, the main ones being: the volume of assistance and individual services are not defined; long waiting times for consultations and necessary examinations from narrow specialists. To assess the scale of these problems, we also used the method of calculating the average number of patients (services) for specific specialists.

In 2019, expert analysis of the state of dispensary observation and the effectiveness of providing specialized medical care to patients with chronic dermatoses was conducted based on the study of primary medical documentation (400 outpatient records of patients with chronic skin diseases registered at the dispensary) and statistical form No. 12 for 2018-2019. As a result of the analysis, it was found that the proportion of patients with diseases of the skin and subcutaneous tissue taken for dispensary observation is low. Therefore, for example, in 2019, in total, diseases of the skin and subcutaneous tissue were registered - 234657 cases (7 302.7 per 100 thousand population), of which for the first time in life - 196 277 cases (6 108.3 per 100 thousand population). There were 10,430 patients on dispensary observation; the coverage of dispensary observation was $4.4 \%$.

Based on the collected information and the results of the analysis, proposals were developed to improve the interaction of the DS and doctors of various specialities, which are coordinated with the main freelance specialists in the profiles; heads of primary health care institutions; General practitioners, etc.

Workshops, meetings, and conferences were held to confirm the feasibility of optimizing the functioning of the DS, including regulatory regulation and planning, and improving the quality of interaction between Dermatovenerologists and doctors of other specialities.

The development of medical and organizational aspects of improving the system of interaction between Dermatovenerologists and doctors of other specialities was carried out by developing local regulations, improving the professional level of training, and creating information support for interaction participants.

\section{DISCUSSION}

The interaction system included both medical processes: improving the provision of all types of medical care in outpatient and inpatient settings, in a day hospital, the introduction of cost-effective forms and methods of medical care; 
and organizational: optimization of the network of skin and venereal institutions, creating an order of interdepartmental interaction, etc. When creating an Order based on a scientific analysis of the main processes of the service, the following management organizational technologies were used. At the first stages of the work, the formula is taken as a basis, according to which the health of the population is the main criterion for the necessary structural and functional transformations in the health care system. Several organizational technologies that are actively used in the region as a whole, including the DS of the region:

- A regional approach to building a network of Dermatovenerological institutions, according to which interdistrict specialized centres are formed to provide the rural population with specialized assistance, assisting the population of several districts that tend to the zonal centre.

- Development of primary health care, including preventive activities of primary care doctors;

- Development of inpatient replacement technologies at all stages of care;

- Inpatient replacement technologies are financial - saving technologies that allow maintaining the quality and increasing the availability of medical care (transferring hospital patients who do not need round-theclock medical supervision to the outpatient stage of treatment, which will reduce the volume of expensive round-the-clock hospitalization and, consequently, the costs of the system).

Mandatory referral to a dispensary (which have more powerful personnel and material and technical potential) of patients with the above diseases has improved the quality of diagnostic, therapeutic and preventive measures. So, in the shortest possible time to make a final diagnosis, prescribe adequate treatment, but the patient on the dispensary register, or, if necessary, send them to inpatient treatment, including in Republican institutions, which helps to reduce the number of complications and severe forms of diseases. ${ }^{3,4}$

As part of the formation of the information society and the introduction of modern information systems, as well as to increase the availability of specialized medical care to patients, an electronic appointment with a Dermatovenerologist "Electronic registry" has been introduced (an anonymous appointment is possible). Patients' satisfaction with the provision of services has increased, as the introduction of electronic records has reduced the waiting time for appointments (patients arrive at the appointed time). The percentage of electronic appointments in 2019 was $58 \%$ of the total.

Work on improving the service and interaction of Dermatovenerologists with doctors of other specialities continues now. Therefore, to improve the quality of medical care for patients with Dermatovenerological profile within the organization of intradepartmental interaction with city clinics where there is no Dermatovenerologist, the "Regulations for interdisciplinary interaction between the dispensary and outpatient clinics of the region" were developed and approved.

\section{CONCLUSION}

The implementation of the developed system of medical and organizational measures, including the formation of a multilevel (district, inter-district and specialized centres) system for providing Dermatovenerological care in the region, the organization of an effective system of interaction between primary medical care, doctors of other specialties and Dermatovenerologists, allow to improve the integration of the efforts of individual stages of the DS (for the period from 2018 to 2019, the number of visits to Dermatovenerologists increased by $10.5 \%$, the coverage rate of dispensary observation of patients with chronic skin diseases increased by 1.5 times) and continuity in the provision of medical care to patients and increase the availability of specialized and highly qualified types of assistance to the entire population, regardless of their place of residence, by getting closer to their place of residence.

\section{ACKNOWLEDGMENT}

Authors acknowledge the immense help received from the scholars whose articles are cited and included in references to this manuscript. The authors are also grateful to authors / editors / publishers of all those articles, journals, and books from which the literature for this article has been reviewed and discussed.

\section{Conflict of Interest: Nil}

\section{Source of Funding: Nil}

\section{REFERENCES}

1. Kubanova AA, Martynov AA, Pirogova EV. Questions of Informatization in dermatovenerology. Collection of abstracts of the 10th anniversary scientific and practical conference of young scientists. Clin Expt Med 2010; 3:18-19.

2. Martynov AA, Pirogova EV. Telecommunication technologies in the process of providing specialized dermatovenerological care.Theses of the XIII International Congress of the interregional public organization.Society for pharmacoeconomic research. Justice Quality Econ Clin Pharmac Pharma 2010; 5:34.

3. Morozova EV, Cartagena OB. medico-organizational measures to improve medical care on the profile of dermatovenereology in the Samara region. Mod Prob Sci Edu 2016;5:231.

4. Pirogova EV, Martynov AA. the current state of information infrastructure of specialized dermatovenerological institutions of the Russian Federation. Top Issues Healt Org Dev 2011;136145. 